\title{
Preface "Sea hazards"
}

\author{
E. Pelinovsky ${ }^{1}$, I. Didenkulova ${ }^{2,3}$, F. Mendez ${ }^{4}$, D. Rybski ${ }^{5}$, and S. Tinti ${ }^{6}$ \\ ${ }^{1}$ Department of Nonlinear Geophysical Processes, Institute of Applied Physics, Nizhny Novgorod, Russia \\ ${ }^{2}$ Laboratory of Wave Engineering, Institute of Cybernetics, Tallinn University of Technology, Tallinn, Estonia \\ ${ }^{3}$ Nizhny Novgorod State Technical University, Nizhny Novgorod, Russia \\ ${ }^{4}$ Environmental Hydraulics Institute "IH Cantabria", Universidad de Cantabria, Santander, Spain \\ ${ }^{5}$ Potsdam Institute for Climate Impact Research, Potsdam, Germany \\ ${ }^{6}$ Dipartimento di Fisica e Astronomia, Università di Bologna, Bologna, Italy
}

Correspondence to: I. Didenkulova (ira@cs.ioc.ee)

\section{Tsunamis}

Tsunamis are the most known and most disastrous sea hazards and can occur in all world oceans as well as in closed or almost closed seas like the Mediterranean. Interest in tsunamis has substantially increased in the last few years, especially after the case of the 2004 Indian Ocean tsunami that devastated the coasts of several near-field and far-field countries and that claimed a death toll of about 220 thousands human lives mostly in Indonesia, India, Sri Lanka and Thailand. Since then and even more after the big Japan tsunami of 11 March 2011, the issues of what we can learn from past experiences and of how coastal communities can be protected from the attack of catastrophic tsunamis have become of paramount importance.

This SI collects a number of papers on the Tohoku tsunami that address different aspects of this event. Choi et al. (2012) study the run-up heights of the 2011 tsunami and compare them with the data from the largest tsunamis that attacked the east Japanese coast in the last $150 \mathrm{yr}$, namely the Meiji Sanriku tsunami of 1896 and the Showa Sanriku tsunami of 1933. The main interest of the authors was the study of the space distribution of the run-up heights along the coast. Data are very abundant for the 2011 tsunami (more than 5000 data points) since the post-event surveys carried out by local experts and by international teams investigated the affected coastal areas (about $300 \mathrm{~km}$ long) with great accuracy. In contrast, the available observations for the 1896 and 1933 tsunamis are quite less (132 and 205, respectively). It was found that the space distribution of the observed run-ups is basically log-normal, which is a confirmation of the original finding on tsunami coastal distribution by Van Dorn (1965) and by Kajiura (1983) who studied tsunami events in Hawaii and in Japan, respectively. What is new in Choi et al.'s (2012) analysis is that the log-normal distribution was proven to be fitted by the experimental data only when they are statistically independent. This issue was not evident while handling data of the historical tsunamis (1896 and 1933) since those data were too few and referring to coastal places usually several kilometers apart (which ensures their independence). Instead, it came to light with the 2011 tsunami where the space density of data is quite larger (many observations were taken in locations very close to each other). It was found that to get statistical independence and log-normal distribution, data should be averaged over a scale not smaller than $7.5 \mathrm{~km}$, which therefore can be taken as a sort of data correlation distance. How this distance is related to basic geomorphological features of the bathymetry and topography of the coastal zone is an issue still unresolved.

The Tohoku tsunami hit the Japan coasts catastrophically, but also reached significant wave heights in very distant coasts after travelling across the Pacific. Numerical codes for tsunami generation and propagation are indispensable tools to compute tsunami radiation from the source areas and to provide adequate estimates of tsunami amplitude and travel times. In operational tsunami warning systems, one of the main constraints is time, since obviously predictions should be made and transmitted to the threatened communities before the tsunami attacks. To meet this requirement, the most common strategy is to pre-compute a database of tsunami scenarios and, in case of tsunami occurrence, to extract the case or cases that are most suited to (i.e. best fit) 
the data from the monitoring networks. This strategy is motivated by the fact that tsunami simulations are usually very time-consuming and there would be no time to run simulations under an impending tsunami. Popinet (2012) argues that adaptive codes can be used instead of fixed-grid numerical codes to cut down the computation time significantly even for propagation over large oceanic areas, which can possibly allow also real-time computations. Indeed Popinet uses an adaptive quadtree-based discretization algorithm to densify cells where it is dynamically needed, i.e. depending on the characteristics of the tsunami waves, which reduces the total number of grid cells and hence of the required mathematical operations. Whereas the computational cost of typical nonflexible tsunami codes increases by a factor of 4 when the grid resolution doubles, adaptive methods tend to confine the cost increase to a factor of 2.60-2.65 (Popinet, 2011), which is a remarkable advantage. The application of this code to the Tohoku tsunami propagation in the near-field (with $250 \mathrm{~m}$ resolution during flooding) and over long oceanic distances (where cells size can be as big as $250 \mathrm{~km}$ ) also provides results in satisfactory agreement with the observations as regards inundation on the Japan coasts and DART buoy records in the far-field.

As already noted above, data for the 2011 Japan tsunami are very abundant and indeed this is the tsunami event with the largest base of data recorded in the whole tsunami history, including coastal tide gauge and offshore buoy records. Bressan and Tinti (2012) analyzed as many as 123 records of tide gauges from most of the countries of the Pacific ocean to study tsunami changes in coastal waters and to test the performance of the tsunami detection algorithm called TEDA: this is devised for real-time detection and is the combination of two threshold algorithms one based on time gradient and the other on an elaborated amplitude of the sea level records (see Bressan and Tinti, 2011, for a detailed description). As regards the TEDA performance, the authors were able to show that the application of the algorithm would have recognized the tsunami quite soon after its arrival in most of the records, typically within the first few minutes corresponding to the first quarter of period, with the exception of records where the tsunami was quite weak, less than $10 \mathrm{~cm}$, since here it was mostly missed (for complete TEDA statistics refer to the quoted paper). Interestingly, on analyzing tsunami first arrivals these authors showed that, despite that the tsunami propagation was rather complex and, as expected, governed by the ocean bottom irregular bathymetry, first arrivals turned out to be well aligned on a distance-time graph with a few exceptions, and with a very small spread, which suggests a constant-speed propagation of the tsunami across the Pacific with phase velocity approximately equal to $206 \mathrm{~m} \mathrm{~s}^{-1}$ corresponding to an average ocean depth of $4330 \mathrm{~m}$ (see Fig. 2 of their paper). One more interesting feature is that recorded periods change from one place to the other, but for most cases they range between $20-60$ min with some outliers that exceed 100 and even $150 \mathrm{~min}$. As for the recorded heights, Bressan and Tinti noted that, though the highest values were measured in the Japanese stations (close to the source; notice however that the tide gauges were destroyed and their data went lost), there is no clear decrease of the tsunami height with distance and very large heights (in excess of $2 \mathrm{~m}$ ) were measured in some of the Hawaiian and of Chilean stations.

Regional tsunami warning systems worldwide are today based on first reaction to large earthquakes. Though in general warning operations are quite complex and though different procedures are established and followed by different warning systems, the starting point of the operational protocol is quite standard for most of them: i.e. the first decision on tsunami occurrence is based on seismic data, more specifically on the earthquake magnitude and hypocentral location, since these determinations can be made in a few minutes (less than 2-3 min) with the present level of technology by using seismic networks and seismic processing procedure of standard quality. Practically, a decision matrix is defined in a way that, on entering earthquake magnitude, hypocentral depth and epicentral distance from the coast, it provides the alert level for the countries in the area covered by the warning center. This first raw-decision bulletin can be later updated as a consequence of more sophisticated analyses made possible by the availability of more data. This strategy has also been defined and approved in the European region, i.e. the last region in the world where tsunami warning centers have been established and have started to be operational. Here, the coordination body of the tsunami warning systems, called ICG/NEAMTWS (Intergovernmental Coordination Group for the North-East Atlantic and Mediterranean Tsunami Warning System), operating in the frame of the IOC (Intergovernmental Oceanographic Commission) within UNESCO, has adopted a specific decision matrix for the entire Mediterranean. Tinti et al. (2012), taking advantage of recent studies revising the Italian seismicity and large earthquakes, and the available tsunami catalogue for the Italian seas (Tinti et al., 2004), studied the predictive efficiency of the decision matrix by applying it retrospectively to the last four centuries of the Italian seismic history, i.e. in the time span when the datasets can be considered complete. They found that this matrix produces quite unsatisfactory results since only in $45-55 \%$ of cases the action prescribed by the matrix is adequate, overestimation takes place in $37 \%$ of cases and underestimation in the rest. The reasons for this failure are partly due to specific local causes and partly to more general ones. The most obvious deficiency is related to the fact that the decision matrix strategy assumes that a tsunami can be generated only as the effect of an earthquake, discarding therefore tsunamis generated by aseismic or seismically-induced landslides and also tsunamis induced by volcanic activity, the latter being comparatively higher in Italy than in several other Euro-Mediterranean areas and being responsible of a number of tsunamis, including the last tsunami event that occurred in Italy in 2002 (Tinti et al., 2006). 
An important development in tsunami early warning systems in the last years has been a move towards the near-field monitoring system, which has been achieved also through the introduction of platforms handling several types of sensors and resulted in more complex warning system architectures. This has been realized for instance in the German Indonesian Tsunami Early Warning System in the Indian Ocean, called GITEWS. A modern state of tsunami warning systems, the direction of their development and future challenges are discussed in Wächter et al. (2012). In particular, it is suggested that the use of Web 2.0 "unconventional" sensor systems, such as Twitter messages, YouTube videos and RSS feeds can be a promising approach for the development of tsunami early warning systems, which provides rapid in situ crowdsourced measurement of the ongoing event.

Since tsunami assessments and forecasts use the information on historical tsunamis (e.g. information about potential tsunamigenic sources, inundation distance, frequency of tsunami occurrence), there is a constant need to improve our knowledge about the historical tsunami records. The relative rarity of tsunami phenomena suggests that for a better understanding it is important to pay attention to all available sources of information about tsunamis, including information about small-scale and "not traditional" tsunamilike events. In this SI an example of these studies is given by Marchenko et al. (2012) who observed a tsunami wave near the glacier front of the Temple Fjord (in the Spitsbergen island, Svalbard archipelago, Norway) infragravity that was probably generated by the glacier motion. This mechanism is similar to tsunami generation by landslides. The tsunami was generated under sea ice and caused its vertical displacement by approximately $30 \mathrm{~cm}$. The authors describe their measurement campaign and the characteristic parameters of the observed wave.

Another possibility to enrich the knowledge of historical tsunamis and also to find new evidence of unknown tsunami events is the geological identification and dating of tsunamis of the past, the so-called paleotsunamis. These approaches allow to extend back the tsunami record up to several millennia. In this SI De Martini et al. (2012) present geological evidence for paleotsunamis along eastern Sicily, Italy. By combining geological information (38 paleotsunami deposits from fine sand layers to boulders collected at 11 sites) with historical data, they reconstruct a unique history of tsunami inundations. As a result, three local unknown tsunamis in the Augusta Bay area have been recognised. Two of them occurred during the first millennium BC and another one in the age interval 650-770 AD. The latter was identified and characterized at 4 different sites for a minimum affected coast length of $145 \mathrm{~km}$. Furthermore, by comparing the historical inundation distance from the shore with geological evidence they showed that historical data tend to underestimate the inundation distance by an order of magnitude.

\section{Extreme sea waves and rogue events}

In the last decades rogue waves have been actively studied theoretically and experimentally. Basic mechanisms of their formation are well described in the recent book by Kharif et al. (2009). The data of rogue waves recorded in different locations all over the world are distributed in various publications. Perhaps, the first attempt to create a catalogue of rogue events that took place worldwide was made by Didenkulova et al. (2006), who analyzed the mass media reports of the year 2005 and were able to recognize the occurrence of nine such events. One year later, Liu (2007) proposed a chronicle of worldwide rogue waves for the period 1498-2007. His collection included 51 events. Recently, Bascheck and Imai (2011) came out with the collection of rogue wave measurements off the US West Coast. The work by Nikolkina and Didenkulova (2011) in this SI is a continuation of these studies and represents a catalogue of rogue waves reported in mass media and associated with damage in 2006-2010. The authors selected as many as 78 rogue events that could be considered reliable, an amount that is large enough to draw preliminary conclusions about statistics of rogue events. In total, during 2006-2010, 131 lives were lost and 196 persons were injured. It is important to mention that rogue waves occurred in both deep and shallow water and at the coast. More information about the observed rogue events during this period is given in the next publication by Nikolkina and Didenkulova (2012).

Although rogue waves are a subject of intense research, consensus on the probability of occurrence of rogue waves has not been achieved. The paper by Bitner-Gregersen and Toffoli (2012) addresses this topic from the perspective of design needs. The authors discuss the occurrence probability of extreme and rogue wave crests in deep water based on numerical simulations, experiments and hindcast data and are able to show that it is higher than the theoretical prediction by Forristall (2000) and can be fitted by the Weibull distribution. Results reveal that rogue waves can actually occur more often than once in the $25 \mathrm{yr}$ period, which is currently used as a return period for ship design.

Zeng and Trulsen (2012) apply modern nonlinear theories, in particular variable-coefficient nonlinear Schrödinger equation, to explain the rogue wave appearance in deep water and study the effect of slowly varying depth on the values of skewness and kurtosis of weakly nonlinear irregular waves propagating from deep to shallower water. Numerical results reveal that kurtosis is smaller at smaller depths. The nonlinear dynamical response of the wave train may occur over a longer domain than the region of depth change, so that the wave train may need a long propagation distance after the slope in order to reach the new equilibrium values for both kurtosis and skewness. The main result of the performed simulations is that the characteristic relaxation distance can be large compared to the local wavelength and the scale of depth change. As a consequence, the waves entering a continental 
shelf from deeper water can have a spatially non-uniform distribution of rogue waves, notably different from that expected from equilibrium statistics at the given depth. Important is that theoretical results are in a good agreement with the data of laboratory experiments (Trulsen et al., 2012). Experimentally it was shown that as relatively long unidirectional waves propagate over a sloping bottom, from a deep to a shallower domain, there can be a local maximum of kurtosis and skewness close to the shallower side of the slope. The probability of large wave envelope has a local maximum near the shallower side of the slope. The described results are obtained for waves at the intermediate water depth for conditions of modulational instability, which are considered to be the main mechanism of a rogue wave formation. However, similar results have been obtained numerically within the variable-coefficient Korteweg-de Vries equation for water waves in a shallow basin of variable depth, which does not allow for the modulational instability (Sergeeva et al., 2011).

Wave-induced extreme water levels in the Puerto Morelos fringing reef lagoon located at the north east of the Yucatan Peninsula (Mexico) are studied by Torres-Freyermuth et al. (2012). Usually, fringing reefs in tropical regions are considered a natural shore protection during extreme wave events. Wave breaking at the shallow reef barrier reduces the energy of high-frequency wind waves, but long or infragravity waves, travelling with the short-wave group, are able to propagate into the reef lagoon with less dissipation. Also a reef barrier provides resonant conditions for water waves leading to wave amplification. Such processes for a given area are studied within 1-D weakly dispersive longwave theory realized in the numerical code SWASH. The model is validated with laboratory experiments and field observations. The model reproduces well-observed high- and low-frequency wave transformation for energetic wave conditions. The numerical results obtained for Puerto Morelos fringing reef lagoon revealed a strong correlation between the offshore sea-swell wave energy and the setup. In contrast, infragravity waves are shown to be the result of a more complex pattern which heavily depends on the reef geometry. Indeed, the southern end of the reef lagoon provides evidence of resonance excitation, suggesting that the reef barrier may act as either a natural flood protection morphological feature, or as an inundation hazard enhancer depending on the incident wave conditions.

\section{Coastal flooding and storm surges}

Not least because of sea level rise, storm surges and coastal floods are of particular interest to researchers, planners, and disaster control managers. This type of natural hazard can represent an enormous threat to human life and economic assets. The complex nature of flood events is rooted in two different regimes, namely (i) physical and (ii) anthropogenic influences. The genesis of storm surges is very diverse and various influences play a role. On the one hand, the coincidence of tidal maxima and meteorological patterns leads to extreme sea levels (Woodworth et al., 2011). On the other hand, wind conditions and bight shape determine local surge heights. Moreover, the location of settlements and assets as well as eventual protection measures affect the risk (Pielke and Downton, 2000). Due to the fact that coastal floods represent events of low probability, empirical studies of damages are very difficult. Damage functions need to be assumed (Boettle et al., 2011) so that future damages and uncertainties can be estimated (Boettle et al., 2013).

This complex of interacting subsystems is addressed by a set of five publications in this SI. One way to tackle the issue is to employ the so-called Source-Pathway-Receptor concept as done by Narayan et al. (2012). The authors aim at structuring large coastal flood systems. The proposed graphical system is illustrated by means of two examples. It is found that the system level analysis performs better than simple topographic maps. Torresan et al. (2012) assess the coastal vulnerability to climate change hazards at the regional scale. The authors develop a regional vulnerability assessment (RVA) methodology to analyse site-specific spatial information on coastal vulnerability with the aim of assisting local communities in operational coastal management and conservation. This work is complemented by Doong et al. (2012) who develop an operational coastal flood early warning system. To this purpose they combine existing sea-state monitoring technology, numerical ocean forecasting models, and historical database. The warning system is exemplified with the Typhoon Haitung (Taiwan 2005). Vatvani et al. (2012) overcome limitations of independent numerical weather prediction and storm surge models by employing the Delft3D storm surge model. It is tested using wind drag parameterization to evaluate the improvements on the storm surge model results. Further, Wahl et al. (2012) follow a statistical approach, employing copula functions. The authors analyze hydrodynamic boundary conditions with the purpose of risk analyses in coastal areas.

\section{References}

Bascheck, B. and Imai, J.: Rogue Wave Observations off the US West Coast, Oceanography, 24, 158-165, doi:10.5670/oceanog.2011.35, 2011.

Bitner-Gregersen, E. M. and Toffoli, A.: On the probability of occurrence of rogue waves, Nat. Hazards Earth Syst. Sci., 12, 751762, doi:10.5194/nhess-12-751-2012, 2012.

Boettle, M., Kropp, J. P., Reiber, L., Roithmeier, O., Rybski, D., and Walther, C.: About the influence of elevation model quality and small-scale damage functions on flood damage estimation, Nat. Hazards Earth Syst. Sci., 11, 3327-3334, doi:10.5194/nhess-113327-2011, 2011.

Boettle, M., Rybski, D., and Kropp, J. P.: How changing sea level extremes and protection measures alter coastal flood damages, Water Resour. Res., 49, doi:10.1002/wrcr.20108, 2013. 
Bressan, L. and Tinti, S.: Structure and performance of a realtime algorithm to detect tsunami or tsunami-like alert conditions based on sea-level records analysis, Nat. Hazards Earth Syst. Sci., 11, 1499-1521, doi:10.5194/nhess-11-1499-2011, 2011.

Bressan, L. and Tinti, S.: Detecting the 11 March 2011 Tohoku tsunami arrival on sea-level records in the Pacific Ocean: application and performance of the Tsunami Early Detection Algorithm (TEDA), Nat. Hazards Earth Syst. Sci., 12, 1583-1606, doi:10.5194/nhess-12-1583-2012, 2012.

Choi, B. H., Min, B. I., Pelinovsky, E., Tsuji, Y., and Kim, K. O.: Comparable analysis of the distribution functions of runup heights of the 1896, 1933 and 2011 Japanese Tsunamis in the Sanriku area, Nat. Hazards Earth Syst. Sci., 12, 1463-1467, doi:10.5194/nhess-12-1463-2012, 2012.

De Martini, P. M., Barbano, M. S., Pantosti, D., Smedile, A., Pirrotta, C., Del Carlo, P., and Pinzi, S.: Geological evidence for paleotsunamis along eastern Sicily (Italy): an overview, Nat. Hazards Earth Syst. Sci., 12, 2569-2580, doi:10.5194/nhess-122569-2012, 2012.

Didenkulova, I. I., Slunyaev, A. V., Pelinovsky, E. N., and Kharif, C.: Freak waves in 2005, Nat. Hazards Earth Syst. Sci., 6, 10071015, doi:10.5194/nhess-6-1007-2006, 2006.

Doong, D.-J., Chuang, L. Z.-H., Wu, L.-C., Fan, Y.-M., Kao, C. C., and Wang, J.-H.: Development of an operational coastal flooding early warning system, Nat. Hazards Earth Syst. Sci., 12, 379390, doi:10.5194/nhess-12-379-2012, 2012.

Forristall, G.: Wave crests distributions: observations and second order theory, J. Phys. Ocean., 30, 1931-1943, 2000.

Kajiura, K.: Some statistics related to observed tsunami heights along the coast of Japan, Tsunamis - Their Science and Engineering, Terra Pub., Tokyo, 131-145, 1983.

Kharif, C., Pelinovsky, E., and Slunyaev, A.: Rogue waves in the ocean, Springer, 216 pp., 2009.

Liu, P. C.: A chronology of freaque wave encounters, Geofizika, 24, 57-70, 2007.

Marchenko, A. V., Morozov, E. G., and Muzylev, S. V.: A tsunami wave recorded near a glacier front, Nat. Hazards Earth Syst. Sci., 12, 415-419, doi:10.5194/nhess-12-415-2012, 2012.

Narayan, S., Hanson, S., Nicholls, R. J., Clarke, D., Willems, P., Ntegeka, V., and Monbaliu, J.: A holistic model for coastal flooding using system diagrams and the Source-Pathway-Receptor (SPR) concept, Nat. Hazards Earth Syst. Sci., 12, 1431-1439, doi:10.5194/nhess-12-1431-2012, 2012.

Nikolkina, I. and Didenkulova, I.: Rogue waves in 2006-2010, Nat. Hazards Earth Syst. Sci., 11, 2913-2924, doi:10.5194/nhess-112913-2011, 2011.

Nikolkina, I. and Didenkulova, I.: Catalogue of rogue waves reported in media in 2006-2010, Nat. Hazards, 61, 989-1006, doi:10.1007/s11069-011-9945-y, 2012.

Pielke Jr., R. A. and Downton, M. W.: Precipitation and damaging floods: Trends in the United States, 1932-97, J. Climate, 13, 3625-3637, 2000.

Popinet, S.: Quadtree-adaptive tsunami modelling, Ocean Dynam., 61, 1261-1285, available at: http://gfs.sf.net/papers/tsunami.pdf, 2011.
Popinet, S.: Adaptive modelling of long-distance wave propagation and fine-scale flooding during the Tohoku tsunami, Nat. Hazards Earth Syst. Sci., 12, 1213-1227, doi:10.5194/nhess-121213-2012, 2012.

Sergeeva, A., Pelinovsky, E., and Talipova, T.: Nonlinear random wave field in shallow water: variable Korteweg-de Vries framework, Nat. Hazards Earth Syst. Sci., 11, 323-330, doi:10.5194/nhess-11-323-2011, 2011.

Tinti, S., Maramai, A., and Graziani, L.: The new catalogue of the Italian tsunamis, Nat. Hazards, 33, 439-465, 2004.

Tinti, S., Maramai, A., Armigliato, A., Graziani, L., Manucci, A., Pagnoni, G., and Zaniboni, F.: Observations of physical effects from tsunamis of December 30, 2002 at Stromboli volcano, southern Italy, Bull. Volcanol., 68, 450-461, 2006.

Tinti, S., Graziani, L., Brizuela, B., Maramai, A., and Gallazzi, S.: Applicability of the Decision Matrix of North Eastern Atlantic, Mediterranean and connected seas Tsunami Warning System to the Italian tsunamis, Nat. Hazards Earth Syst. Sci., 12, 843-857, doi:10.5194/nhess-12-843-2012, 2012.

Torres-Freyermuth, A., Mariño-Tapia, I., Coronado, C., Salles, P., Medellín, G., Pedrozo-Acuña, A., Silva, R., Candela, J., and Iglesias-Prieto, R.: Wave-induced extreme water levels in the Puerto Morelos fringing reef lagoon, Nat. Hazards Earth Syst. Sci., 12, 3765-3773, doi:10.5194/nhess-12-3765-2012, 2012.

Torresan, S., Critto, A., Rizzi, J., and Marcomini, A.: Assessment of coastal vulnerability to climate change hazards at the regional scale: the case study of the North Adriatic Sea, Nat. Hazards Earth Syst. Sci., 12, 2347-2368, doi:10.5194/nhess-12-23472012, 2012.

Trulsen, K., Zeng, H., and Gramstad, O.: Laboratory evidence of freak waves provoked by non-uniform bathymetry, Phys. Fluids, 24, 097101, doi:10.1063/1.4748346, 2012.

Van Dorn, W. G.: Tsunamis, Advances in Hydroscience, edited by: Chow, V. T., Acad. Press, London, 2, 1-48, 1965.

Vatvani, D., Zweers, N. C., van Ormondt, M., Smale, A. J., de Vries, H., and Makin, V. K.: Storm surge and wave simulations in the Gulf of Mexico using a consistent drag relation for atmospheric and storm surge models, Nat. Hazards Earth Syst. Sci., 12, 2399 2410, doi:10.5194/nhess-12-2399-2012, 2012.

Wächter, J., Babeyko, A., Fleischer, J., Häner, R., Hammitzsch, M., Kloth, A., and Lendholt, M.: Development of tsunami early warning systems and future challenges, Nat. Hazards Earth Syst Sci., 12, 1923-1935, doi:10.5194/nhess-12-1923-2012, 2012.

Wahl, T., Mudersbach, C., and Jensen, J.: Assessing the hydrodynamic boundary conditions for risk analyses in coastal areas: a multivariate statistical approach based on Copula functions, Nat. Hazards Earth Syst. Sci., 12, 495-510, doi:10.5194/nhess-12495-2012, 2012.

Woodworth, P. L., Menendez, M., and Gehrels, W. R.: Evidence for centurytimescale acceleration in mean sea levels and for recent changes in extreme sea levels, Surv. Geophys., 32, 603-618, 2011.

Zeng, H. and Trulsen, K.: Evolution of skewness and kurtosis of weakly nonlinear unidirectional waves over a sloping bottom, Nat. Hazards Earth Syst. Sci., 12, 631-638, doi:10.5194/nhess12-631-2012, 2012. 